\title{
Capsaicin responsiveness and cough in asthma and chronic obstructive pulmonary disease
}

\author{
M J Doherty, R Mister, M G Pearson, P M A Calverley
}

\begin{abstract}
Background-Chronic cough is associated with an increased sensitivity to inhaled capsaicin in a number of conditions but there are no data for patients with more severe asthma or chronic obstructive pulmonary disease (COPD). Moreover, the relationships between the capsaicin response (expressed as the concentration of capsaicin provoking five coughs, C5), self-reported cough, and routine medication is not known.

Methods-The cough response to capsaicin in 53 subjects with asthma, 56 subjects with COPD, and 96 healthy individuals was recorded and compared with a number of subjective measures of selfreported cough, measures of airway obstruction, and prescribed medication. In asthmatic subjects the relationships between the cough response to capsaicin and mean daily peak flow variability and nonspecific bronchial hyperresponsiveness to histamine were also examined.
\end{abstract}

Results-Subjects with asthma (median C5 = $62 \mathrm{mM}$ ) and COPD (median C5 = $31 \mathrm{mM}$ ) were similarly sensitive to capsaicin and both were more reactive than normal subjects (median C5 >500 $\mathrm{mM}$ ). Capsaicin sensitivity was related to symptomatic cough as measured by the diary card score in both asthma and COPD $(r=$ -0.38 and $r=-0.44$, respectively), but only in asthma and not COPD when measured using a visual analogue score $(r=\mathbf{0 . 3 2}$ and $r=-0.05$, respectively). Capsaicin sensitivity was independent of the degree of airway obstruction and in asthmatics was not related to $P E F$ variability or $\mathbf{P C}_{20}$ for histamine. The response to capsaicin was not related to treatment with inhaled corticosteroids but was increased in those using anticholinergic agents in both conditions.

Conclusions-These data suggest that an increased cough reflex, as measured by capsaicin responsiveness, is an important contributor to the presence of cough in asthma and COPD, rather than cough being simply secondary to excessive airway secretions. The lack of any relationship between capsaicin responsiveness and airflow limitation as measured by the FEV $_{1}$ suggests that the mechanisms producing cough are likely to be different from those causing airways obstruction, at least in patients with COPD.

(Thorax 2000;55:643-649)

Keywords: asthma; chronic obstructive pulmonary disease; cough reflex
Chronic cough is one of the commonest symptoms of patients with persistent asthma ${ }^{1}$ and may be the sole presenting feature of this disease. ${ }^{2}$ Cough is frequently the first symptom reported by patients with chronic obstructive pulmonary disease (COPD) ${ }^{3}$ and a cough productive of sputum is the cardinal feature of the subset of COPD patients defined as having chronic bronchitis. ${ }^{4}$ However, sputum production is often scanty or absent as COPD progresses, yet cough remains a troublesome problem. $^{5}$

Objective attempts to assess cough sensitivity have yielded conflicting results. When capsaicin, the pungent extract of red pepper, is inhaled it induces cough reproducibly without tachyphylaxis. ${ }^{6}$ Patients with asthma have an increased sensitivity to capsaicin which is most marked in those who complain of cough. ${ }^{7}$ When tested with citric acid, patients with COPD also have an increased cough response but this has not been reported with capsaicin. ${ }^{78}$

These differences could reflect the use of different tussive agents, differing patterns of symptoms, or differences in disease severity. Unfortunately, there are few specific data on spirometry or other symptoms available from the original capsaicin study which examined only 11 patients with COPD. ${ }^{7}$ We hypothesised that the presence of chronic airflow limitation, whether due to asthma or COPD, would be associated with an increased capsaicin cough response, that the cough response would be related to the degree of airflow obstruction, and that the sensitivity to capsaicin would be altered by changing airway calibre. Moreover, we anticipated that there would a relationship between the capsaicin cough threshold and the perceived severity of the cough.

In the absence of an agreed symptomatic measure of cough severity, we have compared several methods of assessing cough as a symptom to the capsaicin response measured in groups of stable chronic asthmatic and COPD patients and have compared the objective data with our previously determined normal range of capsaicin responsiveness.

\section{Methods}

SUBJECTS

We recruited 53 patients with chronic asthma and 56 with COPD from our outpatient clinics. All the asthmatic patients met the conventional diagnostic criteria, ${ }^{9}$ as did those with $\mathrm{COPD}^{10}$ (table 1). The presence of a persistent cough was not necessary for inclusion in the study. All patients were clinically stable and any patient with a history of respiratory tract infection in the preceding four weeks, symptoms or investigations suggestive of oesophageal reflux,

\footnotetext{
19 April 2000

Accepted for publication

19 April 2000

Received 30 April 1999 Returned to author 9 July 1999

Revised version received
} 
Table 1 Demographic features, medication, and physiology of subjects studied

\begin{tabular}{|c|c|c|c|}
\hline & Normal subjects & Asthma & $C O P D$ \\
\hline No. of subjects & 96 & 53 & 57 \\
\hline Median (range) age (years) & $38(20-65)$ & $51(22-73)$ & $65(45-88)$ \\
\hline Sex (\% male) & 34 & 62 & 75 \\
\hline \multicolumn{4}{|l|}{ Smoking habits (\%) } \\
\hline Current smokers & 17 & 17 & 40 \\
\hline Ex-smokers & 20 & 40 & 60 \\
\hline Non-smokers & 63 & 43 & 0 \\
\hline \multicolumn{4}{|l|}{ Drug treatment $(\%)$} \\
\hline$\beta$ agonists & 0 & 100 & 100 \\
\hline Anticholinergics & 0 & 21 & 83 \\
\hline Theophylline & 0 & 8 & 19 \\
\hline Inhaled corticosteroids & 0 & 100 & 35 \\
\hline \multicolumn{4}{|l|}{ Lung function } \\
\hline Mean (SE) FEV ${ }_{1}(1)$ & $3.7(0.48)$ & $2.1(0.12)$ & $1.1(0.1)$ \\
\hline Mean (SE) FVC (1) & $4.4(0.62)$ & $3.4(0.16)$ & $2.6(0.1)$ \\
\hline$\%$ Predicted $\mathrm{FEV}_{1}$ (SE) & $107(14)$ & $71(3)$ & $42(2)$ \\
\hline Mean (SE) PEF variability (\%) & - & $\begin{array}{l}15.9(1.2) \\
(\mathrm{n}=53)\end{array}$ & $\begin{array}{l}17.0(1.8) \\
(\mathrm{n}=18)\end{array}$ \\
\hline Mean (SE) $\mathrm{PC}_{20}(\mathrm{mg} / \mathrm{ml})$ & - & $\begin{array}{l}1.9(0.46) \\
(\mathrm{n}=43)\end{array}$ & - \\
\hline
\end{tabular}

$\mathrm{FEV}_{1}=$ forced expiratory volume in one second $; \mathrm{FVC}=$ forced vital capacity $\mathrm{PEF}=$ peak expiratory flow; $\mathrm{PC}_{20}=$ concentration of histamine provoking a fall in $\mathrm{FEV}_{1}$ of $20 \%$ or more.

Values are numbers of subjects except when otherwise stated.

subjects taking angiotensin converting enzyme inhibitors, or those less than 18 years of age were excluded, although there was no upper age limit. No patient had clinical or radiographic features suggestive of co-existing bronchiectasis. We excluded patients with a history of allergic rhinitis, post nasal drip, and those being treated for nasal symptoms. The data were compared with those derived from our normal subject population recruited from hospital staff, free from respiratory disease, who denied cough and were not receiving any medication. All subjects gave written informed consent to the study which was approved by our institutional ethical committee.

PROCEDURES

Subjects omitted short acting inhaled $\beta$ agonists and anticholinergic agents for six hours before attendance and longer acting drugs such as oral theophylline or inhaled long acting $\beta$ agonists for 12 hours on all test days. All subjects underwent the following tests.

\section{Spirometry}

Spirometric parameters were recorded with a wedge spirometer (Vitalograph, Maidenhead, Berkshire, UK) and the best forced expiratory

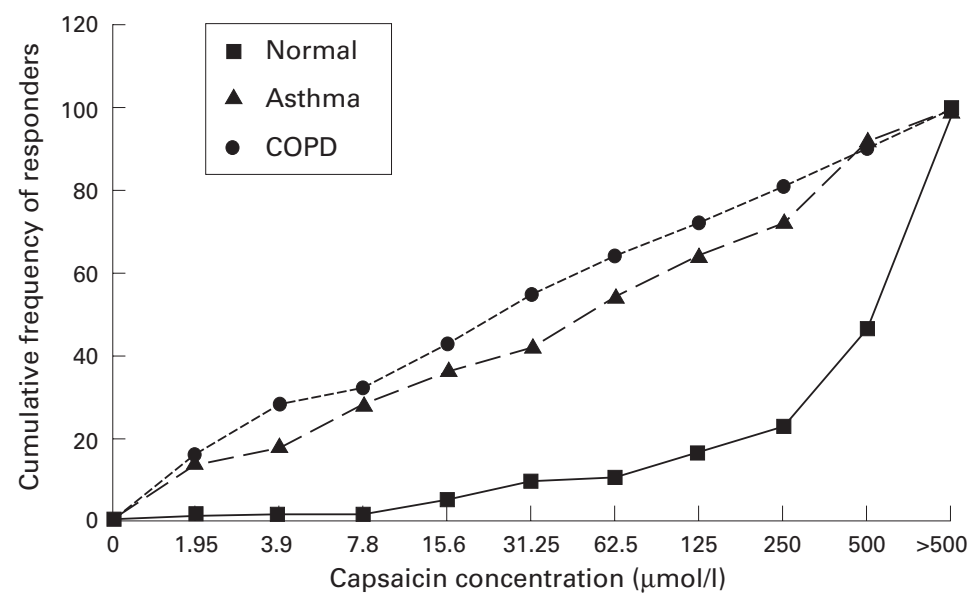

Figure 1 Comparison of the cumulative frequency at which subjects reached the $C 5$ response for asthma and for subjects with COPD compared with normal subjects. volume in one second $\left(\mathrm{FEV}_{1}\right)$ and forced vital capacity (FVC) traces from three technically satisfactory attempts were used. Data are expressed as percentage predicted values. ${ }^{11}$

Capsaicin cough challenge

Capsaicin (Sigma Chemical Co, St Louis, Missouri, USA) was dissolved in absolute ethanol to make a stock solution of $10^{-2} \mathrm{M}$ which was further diluted with $0.9 \%$ saline to produce nine doubling concentrations from 2 to $500 \mu \mathrm{M}$. Doses were administered from an Acorn nebuliser powered from a dosimeter calibrated to deliver $0.009 \mathrm{ml}$ in each inhalation at a maximum flow rate of $0.75 \mathrm{l} / \mathrm{s}$ and a mass median particle diameter of $5.2 \mu \mathrm{m}$. Subjects were asked to take a single slow inhalation from the dosimeter beginning with saline control and then, with a minimum of 30 second intervals, increasing strengths of capsaicin until a given inhalation caused five coughs (C5). This dose was repeated to ensure that a reproducible C5 response had been attained and, if so, that the value was recorded as the patient's value (C5 capsaicin).

\section{COPD: additional tests}

Subjects with COPD then completed the following additional tests:

(1) Diary cards: these were completed at home over a two week period during which the subject recorded symptom scores or daily cough on a five point scale ranging from $1=$ no cough to $5=$ distressing cough most of the day. The score over the 14 day recording period was used to calculate the mean daily diary cough score. Peak expiratory flow (PEF) was self-recorded using a mini Wright peak flow meter four times a day in a standard fashion, the best of three measurements being taken. Peak flow variation for any particular day was taken as the difference between the highest and lowest peak flow divided by the highest measure. For patients with more than nine days of complete data the mean daily PEF variability was calculated.

(2) Hospital questionnaire: a detailed history of current respiratory medications was obtained with particular note of 'as needed' inhaled $\beta$ agonists, regular inhaled anticholinergic agents, and inhaled corticosteroids (table 1). Sputum production was recorded as nil, occasional, or frequent. Symptoms of cough were recorded in a number of ways:

(a) the presence or absence of cough on most days;

(b) whether this cough was mild, moderate, or severe;

(c) using a $10 \mathrm{~cm}$ visual analogue scale (VAS) marked between no cough at one end and worst imaginable cough at the other end.

Further tests

After the above, patients with asthma and COPD were invited to perform further tests including lung volume measurement, histamine challenge tests, and the effect of bronchodilators on the $\mathrm{C} 5$ response. Histamine challenge tests were performed later the same day while lung volume estimation and effect of bronchodilators were measured on separate 
study days during the following three weeks. In those with asthma the subgroup studied depended solely on the patient's willingness to undergo these investigations. In those with COPD some patients were unable to take a further part as they were about to enrol in another clinical trial, and others were only willing to some of the extra tests. There was no difference in mean age, percentage predicted $\mathrm{FEV}_{1}$, or median C5 response between the subgroups who underwent additional tests and their parent cohorts.

(1) Static lung volumes and flow-volume loops: 38 patients with asthma and 20 with COPD performed flow-volume loops and measurement of static lung volumes while seated using a rolling seal spirometer (PK Morgan Ltd) with standard criteria for an acceptable loop. ${ }^{11}$ After coaching, each subject performed repeated loops until three technically satisfactory traces were obtained. The
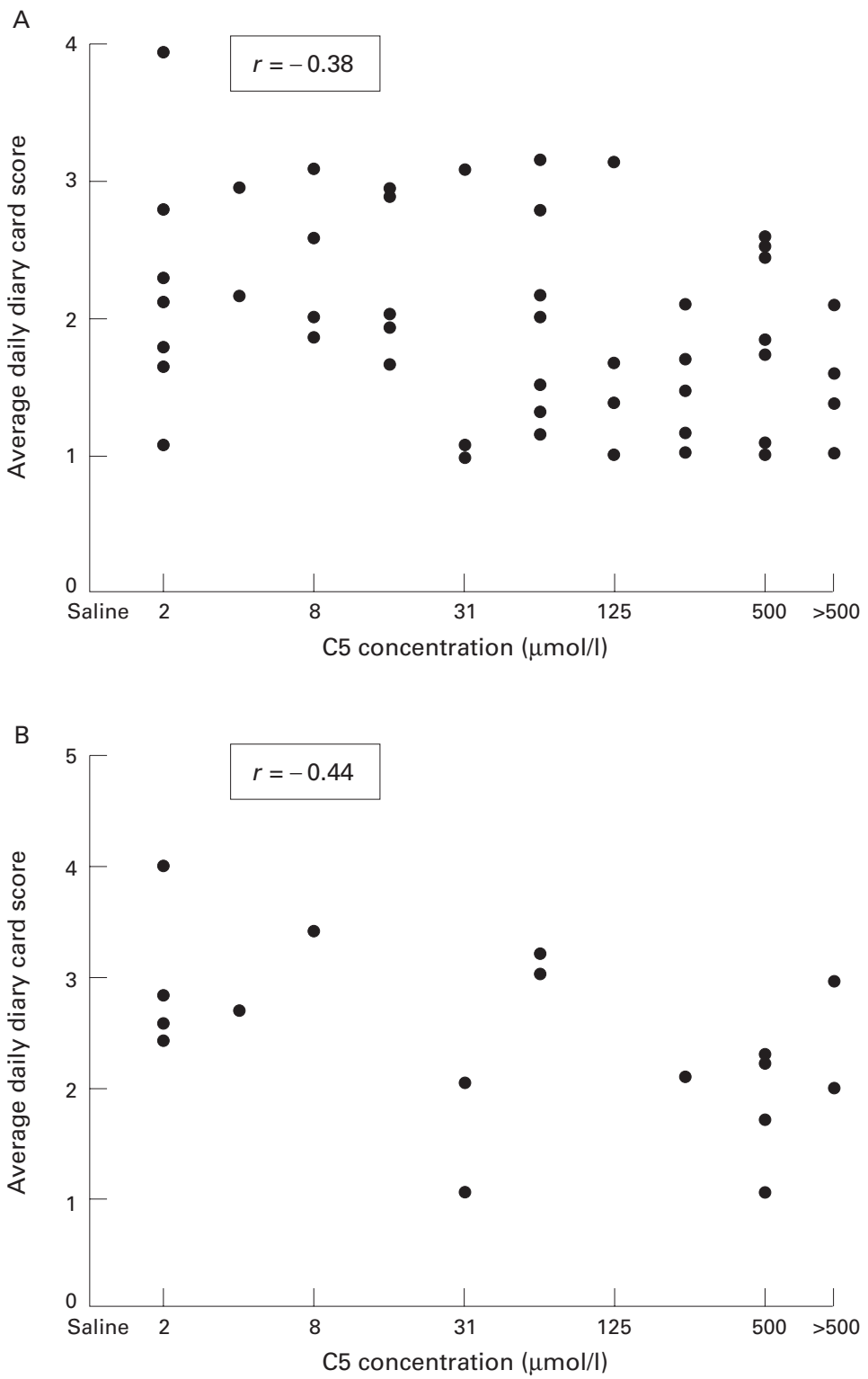

Figure 2 Scatter plots with Spearman correlation coefficients showing the relationship between self-reported cough measured using the daily diary card cough scores and capsaicin responsiveness (C5) for $(A)$ asthma and $(B) C O P D$. loop with the largest sum of $\mathrm{FEV}_{1}$ and $\mathrm{FVC}$ was chosen and from this loop PEF, 25-75\% forced expiratory flow $\left(\mathrm{FEF}_{25-75}\right)$, and peak inspiratory flow (PIF) were derived. Static lung volumes were measured using the helium dilution technique.

(2) Histamine challenge: 43 asthmatic patients performed histamine challenge testing 15 minutes after the capsaicin study, inhaling from a dosimeter in a standard fashion. The $\mathrm{FEV}_{1}$ was recorded before the histamine challenge to ensure that there was no change from the pre-capsaicin baseline. The concentration of histamine provoking a fall in $\mathrm{FEV}_{1}$ of $20 \%$ or more $\left(\mathrm{PC}_{20}\right)$ was calculated by linear interpolation from the logarithmic concentration response curve.

(3) Effect of changing airway calibre on the C5 response: 40 patients with asthma and 13 with COPD performed a capsaicin challenge test and spirometric measurements both before and 30 minutes after each $5 \mathrm{mg}$ nebulised salbutamol, $500 \mu \mathrm{g}$ nebulised ipratropium bromide, and $3 \mathrm{ml} 0.9 \%$ saline. All solutions were given using a System 22 Acorn nebuliser on separate days at the same time of the day in random double blind order. For each disease group and for each solution the $\mathrm{C} 5$ and $\mathrm{FEV}_{1}$ values before and after administration of the nebulised agents were compared. Twenty three asthmatics performed a capsaicin challenge both before and immediately after the histamine challenge so that, at the time of the second histamine challenge, their $\mathrm{FEV}_{1}$ was reduced by at least $20 \%$ from baseline. The effects of bronchoconstriction were then studied by comparing the difference between the C5 before and after the histamine challenge test with the difference between each subject's C5 response before and after saline.

\section{STATISTICAL ANALYSIS}

Median C5 values and the frequency distribution were used to describe the normal range in each disease group. These were then compared using the Kruskal Wallis test followed, if significant, by paired Mann-Whitney $U$ tests between the groups.

The relationship between symptoms and sensitivity to capsaicin was examined in a number of ways. The average daily diary card cough score and the visual analogue score derived from the questionnaire were each related to the C5 of each subject using Spearman rank correlation coefficient within each disease group. Patients were grouped into those who did and those did not cough on most days and were then compared using Mann-Whitney U tests. Subjects were also divided into those who considered their cough to be mild, moderate, or severe and these groups were compared using the Kruskal Wallis test. Similarly, subjects with asthma and COPD were subdivided into those who rarely produced phlegm, those who occasionally produced phlegm, and those who usually produced phlegm and these groups were again compared using the Kruskal Wallis test. Lung function data are presented as mean (SE). The relationship between capsaicin sensitivity and 
Table 2 Severity of self-reported cough in subjects with asthma and COPD using a variety of measures, and its relationship to regular treatment

\begin{tabular}{|c|c|c|c|c|c|c|c|c|}
\hline & \multirow[b]{2}{*}{$n$} & \multicolumn{3}{|l|}{ Asthma } & \multirow[b]{2}{*}{$n$} & \multicolumn{3}{|l|}{$C O P D$} \\
\hline & & & & $\begin{array}{l}\text { Median } C 5 \\
(\mu M)\end{array}$ & & & & $\begin{array}{l}\text { Median } C 5 \\
(\mu M)\end{array}$ \\
\hline Cough present & 43 & $\begin{array}{l}\text { Cough most days } \\
\text { No cough most days }\end{array}$ & $\begin{array}{l}61 \% \\
39 \%\end{array}$ & $\begin{array}{l}16 \\
250 \\
(p=0.015)\end{array}$ & 57 & $\begin{array}{l}\text { Cough most days } \\
\text { No cough most days }\end{array}$ & $\begin{array}{l}81 \% \\
9 \%\end{array}$ & $\begin{array}{l}31 \\
31 \\
(p=0.8)\end{array}$ \\
\hline Severity of cough & 43 & $\begin{array}{l}\text { Mild } \\
\text { Moderate } \\
\text { Severe }\end{array}$ & $\begin{array}{l}54 \% \\
37 \% \\
10 \%\end{array}$ & $\begin{array}{l}125 \\
63 \\
16 \\
(p=0.014)\end{array}$ & 57 & $\begin{array}{l}\text { Mild } \\
\text { Moderate } \\
\text { Severe }\end{array}$ & $\begin{array}{l}31 \% \\
56 \% \\
12 \%\end{array}$ & $\begin{array}{l}125 \\
16 \\
8 \\
(p=0.1)\end{array}$ \\
\hline Sputum production & 43 & $\begin{array}{l}\text { Usually } \\
\text { Occasionally } \\
\text { Rarely }\end{array}$ & $\begin{array}{l}51 \% \\
28 \% \\
21 \%\end{array}$ & $\begin{array}{l}16 \\
125 \\
500 \\
(p=0.014)\end{array}$ & 57 & $\begin{array}{l}\text { Usually } \\
\text { Occasionally } \\
\text { Rarely }\end{array}$ & $\begin{array}{l}56 \% \\
26 \% \\
16 \%\end{array}$ & $\begin{array}{l}31 \\
31 \\
125 \\
(p=0.8)\end{array}$ \\
\hline Anticholinergic therapy & 53 & $\begin{array}{l}\text { Prescribed } \\
\text { Not prescribed }\end{array}$ & $\begin{array}{l}21 \% \\
79 \%\end{array}$ & $\begin{array}{l}8 \\
125 \\
(p=0.02)\end{array}$ & 57 & $\begin{array}{l}\text { Prescribed } \\
\text { Not prescribed }\end{array}$ & $\begin{array}{l}82 \% \\
18 \%\end{array}$ & $\begin{array}{l}31 \\
250 \\
(p=0.03)\end{array}$ \\
\hline $\begin{array}{l}\text { Inhaled corticosteroid } \\
\text { therapy }\end{array}$ & 53 & $\begin{array}{l}\text { Low dose } \\
\text { Moderate dose } \\
\text { High dose }\end{array}$ & $\begin{array}{l}26 \% \\
62 \% \\
12 \%\end{array}$ & $\begin{array}{l}93 \\
63 \\
125 \\
(p=0.7)\end{array}$ & 57 & $\begin{array}{l}\text { Prescribed } \\
\text { Not prescribed }\end{array}$ & $\begin{array}{l}35 \% \\
65 \%\end{array}$ & $\begin{array}{l}63 \\
31 \\
(p=0.6)\end{array}$ \\
\hline
\end{tabular}

$\mathrm{PC}_{20}$ for histamine was examined using Spearman rank correlation coefficient as was that for the $\mathrm{C} 5$ response and lung function. Both pre and post nebuliser $\mathrm{C} 5$ and $\mathrm{FEV}_{1}$ values as well as pre and post histamine $\mathrm{C} 5$ and $\mathrm{FEV}_{1}$ values were compared using Mann-Whitney U tests.

\section{Results}

The clinical and physiological data at study entry are given in table 1 . The patients with asthma were older than the normal subjects but younger than the patients with COPD $(p<0.001)$ and almost $60 \%$ had been or were cigarette smokers. The median $\mathrm{C} 5$ was reduced in both asthma $(62.5 \mu \mathrm{M})$ and COPD $(31.2 \mu \mathrm{M})$ compared with the healthy controls $(>500 \mu \mathrm{M}, \mathrm{p}<0.001$, fig 1$)$. There were no significant differences in the median or in the distribution of the C5 responses between the asthmatic and COPD patients.

ASTHMA SYMPTOMS AND LUNG FUNCTION

Diary card data for the 53 patients with asthma showed a mean (SE) daily cough score of 1.96 (0.1) which was inversely correlated with the C5 concentration $(r=-0.38, \mathrm{p}<0.05$; fig $2 \mathrm{~A})$. Hospital questionnaire data using the VAS assessment of cough were correlated with the mean diary cough score in the 43 patients for whom both were available $(r=0.40, \mathrm{p}<0.05)$. The VAS scores were more variable than the diary card scores, ranging from 0 to $8.5 \mathrm{~cm}$, but they showed a similar weak correlation with the C5 values $(r=-0.32, \mathrm{p}<0.05)$.

The distribution of the responses to specific questions about the perception of cough are given in table 2 . The presence of any cough, of a productive cough, and the patient's assessment of cough severity were all related to an increased cough response and to a lower percentage predicted $\mathrm{FEV}_{1}$. However, overall there was no significant correlation between either the absolute $\mathrm{FEV}_{1}$ or the percentage predicted $\mathrm{FEV}_{1}$ and the measured C5 response (fig 3). The cough response was not related to whether or not subjects were current smokers or to the dose of inhaled corticosteroids taken. However, those patients using an inhaled anticholinergic drug did have a greater C5 sensitivity $(\mathrm{p}=0.002$; fig $3 \mathrm{~A})$. The C5 response of those patients not treated in this way was still significantly greater than that of the normal subjects.

\section{COPD SYMPTOMS AND LUNG FUNCTION}

Complete symptomatic data were available in only 19 cases, the remaining patients having been recruited into a study of inhaled corticosteroids where treatment changes might have affected the data. These patient groups did not differ significantly in their smoking habit, percentage predicted $\mathrm{FEV}_{1}$, or median C5. They reported a higher daily cough score than the asthmatic subjects $(2.36(0.18)$ versus 1.96 (0.1)) but this difference was not significant. As for asthma, there was a correlation between the cough score and the mean C5 response $(r=$ -0.44 , $\mathrm{p}<0.05$; fig $2 \mathrm{~B}$ ).

Data on the response of COPD patients to the cough questionnaire are given in table 2. Apart from a non-significant trend for the patients with 'severe' cough to have an increased sensitivity to capsaicin $(p=0.1)$, there were no associations between the presence or absence of symptoms and either C5 or $\mathrm{FEV}_{1}$ (fig 4). Similarly, there was no association between the recorded $\mathrm{C} 5$ and current smoking status or the use of inhaled corticosteroids. However, those patients using inhaled anticholinergic treatment had an increased $\mathrm{C} 5$ response compared with those not so treated ( $p<0.03$; fig 3C), the remaining subjects still having a greater C5 response than the healthy controls.

\section{C5 AND THE EFFECTS OF RESTING LUNG} FUNCTION AND ACUTE CHANGES IN AIRWAY CALIBRE

C5 values were independent of all the parameters derived from the flow-volume loop and of the static lung volumes. In patients with asthma C5 was unrelated to the diurnal PEF variability or to the baseline $\mathrm{PC}_{20}$ histamine. In the 40 patients tested before and after bronchodilators 
A

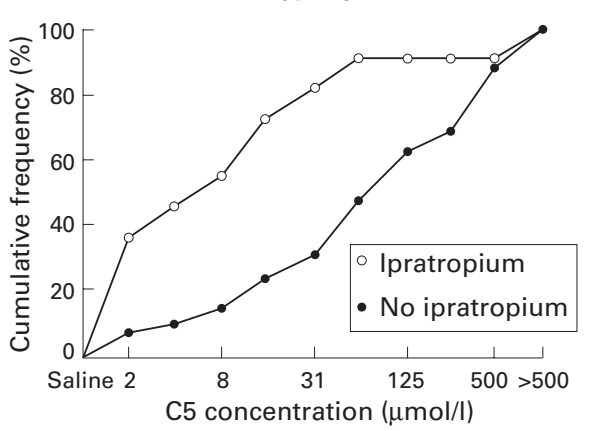

B

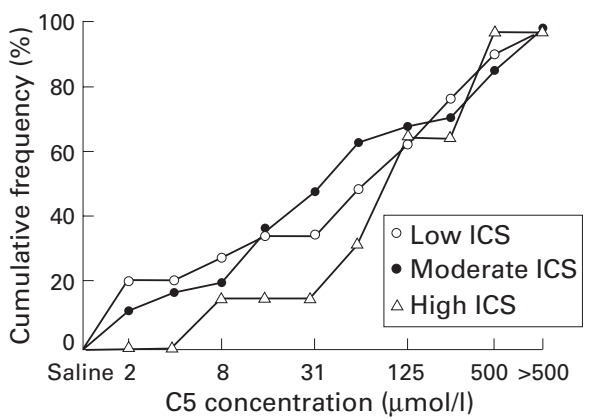

C

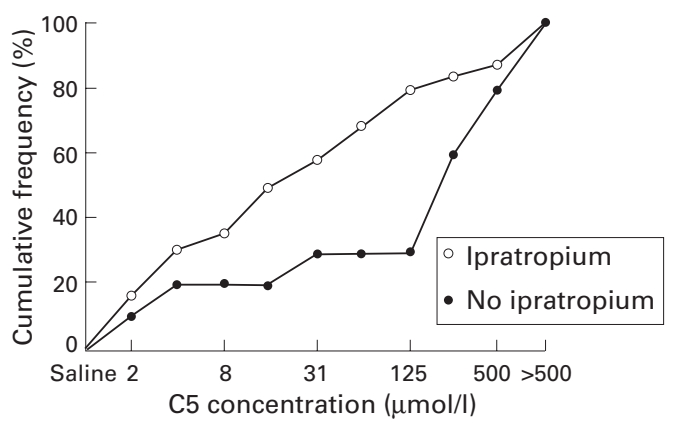

D

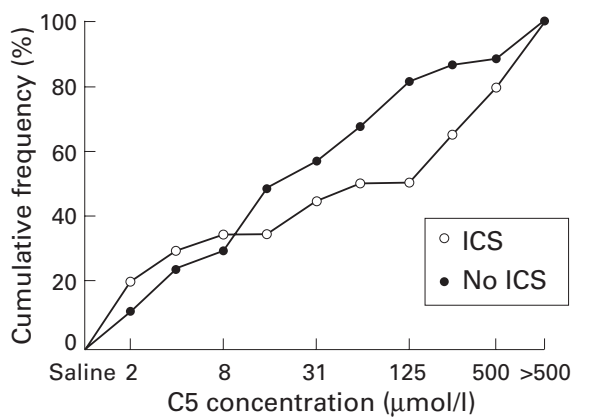

Figure 3 Comparison of the cumulative frequency at which subjects reached the $C 5$ response by medication for both asthma and for COPD: (A) asthma: inhaled anticholinergics versus no inhaled anticholinergics; (B) asthma: low versus moderate versus high dose inhaled corticosteroids; $(C)$ COPD: inhaled anticholinergics versus no inhaled anticholinergics, (D) COPD: inhaled corticosteroids versus no inhaled corticosteroids.

a mean increase in $\mathrm{FEV}_{1}$ of 0.37 (0.04) 1 after salbutamol or $0.36(0.04) 1$ after ipratropium from a baseline of $2.07(0.13) 1$ did not change the median $\mathrm{C} 5$ response. Similarly, the median C5 values were unchanged in the 23 asthmatic patients measured before and after histamine challenge, despite a fall in $\mathrm{FEV}_{1}$ of a mean of 0.6 (0.05) 1 from a baseline value of $2.1(0.12) 1$.

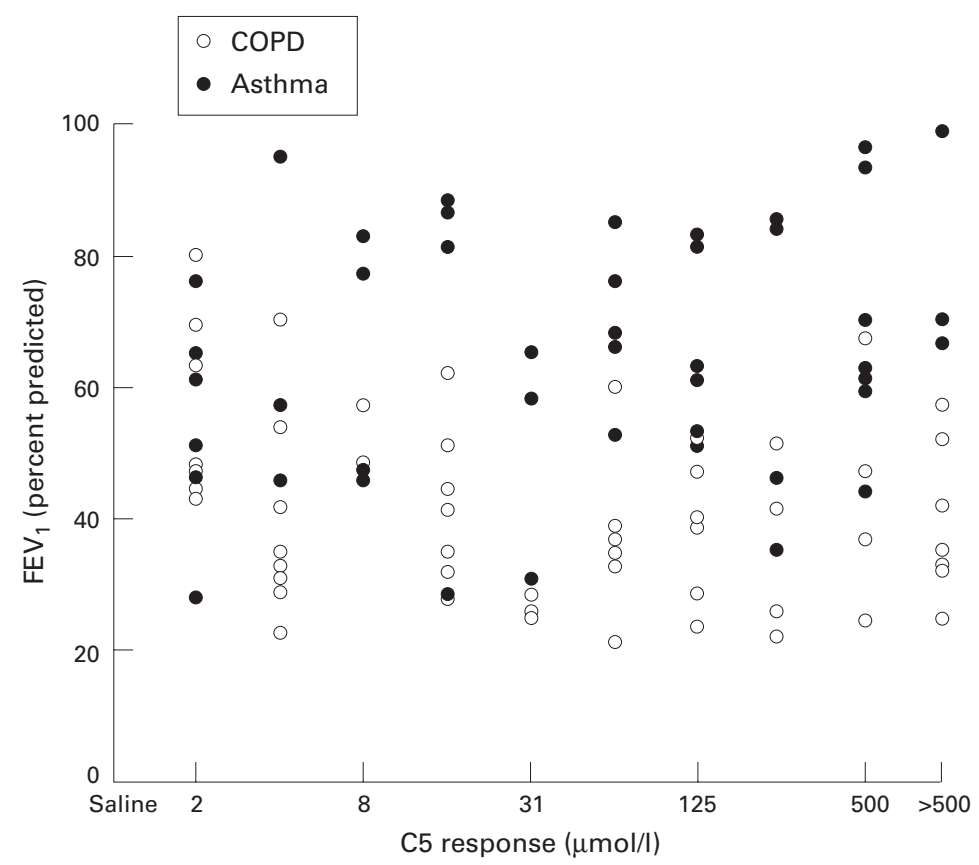

Figure 4 Scatter plot showing the relationship between $C 5$ response and percentage predicted $\mathrm{FEV} V_{1}$ for both asthma and COPD
In the 13 patients with COPD tested before and after bronchodilators the $\mathrm{FEV}_{1}$ rose from $1.2(0.12) 1$ to $1.37(0.13) 1$ after salbutamol and to $1.41(0.14) 1$ after ipratropium, but without a significant effect on the measured C5 response.

\section{Discussion}

The capsaicin cough challenge test is a simple and reproducible laboratory method for the assessment of cough susceptibility in a wide range of diseases. ${ }^{72}$ It tests the afferent limb of the cough reflex which is thought to be mediated by rapidly adapting receptors within the airway wall. It can be increased by inhaling prostanoids in normal subjects ${ }^{13}$ or by taking a thromboxane antagonist in patients with asthma. ${ }^{14}$

Studies in a range of conditions associated with chronic cough have shown an increased capsaicin sensitivity that falls with successful treatment, which can be achieved in two thirds of cases. ${ }^{12}$ However, it is difficult to extrapolate data from these studies to patients with either asthma or COPD as the numbers studied, particularly in the latter group, are relatively small and data about lung function and bronchial reactivity are scanty. Our data in a large group of chronic persistent asthmatic subjects extend earlier observations in mild asthma that suggested that a reduced C5 cough threshold is a frequent finding which bears some relationship to the severity of the patient's symptoms. Other measures such as percentage predicted $\mathrm{FEV}_{1}$ have recently been shown not to relate to the severity of cough in asthmatic subjects. ${ }^{15}$ 
Similar reductions in cough threshold were seen in patients with moderate to severe COPD, despite the significant differences in the baseline spirometric values and the different mechanisms producing the disease. ${ }^{16}$

Several methodological problems should be addressed. We performed our capsaicin challenge as described previously ${ }^{7}$ with the additional feature of repeating the last concentration inhaled to confirm the $\mathrm{C} 5$ end point. We did not report the concentration producing two coughs (C2) as we have found this to be less reproducible than the $\mathrm{C} 5$ response in normal subjects and it does not add additional information. Others using similar methods have also found that $\mathrm{C} 2$ and $\mathrm{C} 5$ data yield similar information in other diseases. ${ }^{18}$ As challenge test dosimeters are not identical, we have related changes in our patients to our laboratory's normal values rather than to those derived from the literature, although our normal range overlaps that described elsewhere. We used a fixed inspiratory flow rate to minimise differences in cough threshold between subjects. ${ }^{17}$ In our laboratory we have found no evidence of age, sex, or smoking effects, unlike other reports. ${ }^{18}$

The reduced $\mathrm{C} 5$ in patients with chronic stable asthma was not surprising in view of the earlier reports in milder disease. A range of possible mechanisms involving different inflammatory mediators has been suggested to explain the enhanced C5 response. ${ }^{13}{ }^{12}$ However, given the heterogeneity of $\mathrm{FEV}_{1}$ and $\mathrm{PC}_{20}$ of the asthmatic populations in which this has now been reported, it seems likely that increased cough susceptibility is either produced by very non-specific means or involves an entirely different pharmacological pathway from the mechanisms which determine the severity of airways reactivity or resting airway calibre. This has implications for the modification of cough as a symptom in asthma.

The reduction in C5 in the patients with COPD was unexpected as previous reports had suggested that the $\mathrm{C} 5$ response was normal in COPD and that the cough was perhaps related to increased sputum production and now increased responsiveness of laryngeal receptors. $^{21}$

Studies in patients with chronic bronchitis or COPD where lung function data are available have examined less severe disease and/or a population diagnosed as having chronic sinus disease, ${ }^{22}$ neither being representative of unselected COPD patients reported here. Our patients met the conventional diagnostic criteria for COPD, had limited bronchodilator reversibility and a history of past or current smoking, making it unlikely that there was a significant asthmatic element to their illness. In these patients we found no association between reported sputum production and either cough severity or C5 threshold.

Induced sputum studies have shown levels of pro-inflammatory cytokines in both asthma and COPD. ${ }^{23}{ }^{24}$ Persistent airway inflammation may contribute to the enhanced $\mathrm{C} 5$ response and merits further investigation.
The confounding effects of drug treatment or smoking are unlikely to explain our findings. Regular use of $\beta$ agonists does not appear to modify the $\mathrm{C} 5$ response, despite earlier reports of benefit in cough induced in volunteers, ${ }^{25}$ and our patients were asked to omit inhaled therapy before attendance. Short term use of oral corticosteroids and longer term use of inhaled corticosteroids are associated with changes in the frequency of symptomatic cough in COPD ${ }^{26}$ Specific data about the effect of these drugs on cough threshold are lacking. We found no relationship between smoking status and $\mathrm{C} 5$, neither did the regular use of $\beta$ agonists or inhaled corticosteroids relate to the recorded response. Likewise, there were no differences in the symptom severity of cough, however assessed, and the presence of sputum production or use of inhaled corticosteroids. We found that the C5 cough threshold was significantly lower in both asthmatic and COPD patients taking regular inhaled ipratropium, although the patients not using these drugs were still more responsive than the control subjects. Whilst it is tempting to postulate that this may be a pharmacological effect, it is more likely to reflect selection of the more severe patients among the asthmatic group ${ }^{9}$ and the widespread use of these drugs among COPD patients. ${ }^{10}$ Indeed, anticholinergic agents have been shown to decrease rather than increase the nasal response to capsaicin. ${ }^{27}$ Prospective studies of the capsaicin response before and after the introduction of anticholinergic treatment would be needed entirely to exclude this as an adverse reaction to treatment.

Whilst differences in the deposition of capsaicin to more central airway receptors might be hypothesised to explain some of the apparent similarities in asthmatic and COPD patients, the absence of any relationship between C5 and the severity of airflow limitation is a pointer against this. None of the measures of airflow limitation were related to C5 in either disease. Moreover, the C5 was unaltered even when the airway calibre was varied acutely, suggesting that neither airflow limitation alone nor changes in capsaicin deposition explain the increased level of response in our patients with asthma or COPD. A similar lack of effect of smaller changes in airway calibre has been reported in normal subjects, ${ }^{25}$ but our data confirm that this is true in established disease when baseline $\mathrm{FEV}_{1}$ is reduced.

C5 was not related to the level of bronchial hyperreactivity or to the level of PEF variability over two weeks, providing further evidence that the mechanisms underlying cough production are not necessarily related to those determining airway calibre.

Unlike previous studies, our patients were not selected because of their complaint of cough $^{12}{ }^{17}$ but were randomly drawn from our outpatient clinics as we did not wish to bias our data by patients self-selected by their perception of a subjective complaint. Most patients, whatever the diagnosis, rated their cough as being of either mild or moderate severity, but the capsaicin response did not distinguish between these subjective grades. Other 
mechanisms may be important in milder disease, but this discrepancy is more likely to reflect the relative insensitivity of assessing cough from a single interview. Perceptions about coughing reported at the hospital visit were poorly related to severity as assessed from the diary card data. However, patients with the most troublesome cough did have significantly lower C5 responses. In general, the agreement between symptom severity and the $\mathrm{C} 5$ response was somewhat better in the asthmatic subjects than in those with COPD. We should be cautious in interpreting group data showing symptomatic and C5 improvements with treatment in these diseases as the subjective and objective measurements may not necessarily change in the same way in an individual. This is in contrast to other forms of chronic cough such as that induced by ACE inhibitors where symptom severity and C5 are in good agreement in the individual before and after withdrawal of the drug. ${ }^{28}$

Our data show that a reduced cough threshold is a frequent finding in airways disease, whether associated with asthma or COPD. Reliance on one measure of self-reported coughing can be difficult to interpret, particularly in COPD. Use of the capsaicin challenge gives objective information about cough susceptibility which may prove more discriminatory than just questioning about the presence or absence of cough or sputum production. The relative role of this mechanism and its relationship to the effects of other agents such as citric acid or low $\mathrm{Cl}^{-}$as the disease progresses merits further study. The mechanisms producing increased capsaicin responsiveness, whether inflammatory or mediator driven, also require further exploration, particularly in patients with COPD where an abnormal cough threshold appears to be relatively common.

1 Irwin RS, Corrao WM, Pratter MR. Chronic persistent cough in the adult: the spectrum and frequency of causes and successful outcome of specific therapy. Am Rev Respir Dis 1981;123:413-7.

2 Corrao WM, Braman SS, Irwin RS. Chronic cough as the sole presenting manifestation of bronchial asthma. $N$ Engl $f$ Med 1979;300:633-7.

3 Burrows B, Niden AH, Barclay WR, et al. Chronic obstructive lung disease. II. Relationship of clinical and physiological findings to the severity of airway obstruction. Am Rev Respir Dis 1965;91:665-78.

4 CIBA Guest Symposium Report. Terminology, definitions and classification of chronic pulmonary emphysema and related conditions. Thorax 1959;14:286-99.

5 Pearson MG, Calverley PMA. Clinical and laboratory assessment. In: Calverley PMA, Pride NB, eds. Chronic obstructive pulmonary disease. London: Chapman and Hall, obstructive pulmonc

6 Morice AH, Higgins KS, Yeo Ww. Adaptation of cough reflex with different types of stimulation. Eur Respir $\mathcal{F} 1992$ 5:841-7.
7 Choudry NB, Fuller RW. Sensitivity of the cough reflex in patients with chronic cough. Eur Respir F 1992;5:296-300. 8 Simonsson BG, Jacobs FM, Nadel JA. Role of autonomic nervous system and the cough reflex in the increased responsiveness of airways in patients with obstructive airway disease. $\mathcal{F}$ Clin Invest 1967;46:1812-8.

9 British Thoracic Society, National Asthma Campaign, Royal College o Physicians of London, et al. The British guidelines on asthma management: 1995 review and position statement. Thorax 1997;52(Suppl 1):S1-21.

10 COPD Guidelines Group of the Standards of Care Committee of the BTS. BTS guidelines for the management of chronic obstructive pulmonary disease. Thorax 1997;52(Suppl 5):S1-28.

11 Quanjer PH, Tammeling GJ, Cotes JE, et al. Lung volumes and forced ventilatory flows. Report of the Working Party on Standardization of Lung Function Tests, European Community for Steel and Coal. Official Statement of the European Respiratory Society. Eur Respir F Suppl 1993;16: Europ

12 O'Connell F, Thomas VE, Pride NB, et al. Capsaicin cough sensitivity decreases with successful treatment of chronic cough. Am f Respir Crit Care Med 1994;150:374-80.

13 Choudry NB, Fuller RW, Pride NB. Sensitivity of the human cough reflex: effect of inflammatory mediators prostaglandin E2, bradykinin, and histamine. Am Rev Respir Dis 1989;140:137-41.

14 Fujimura M, Kamio Y, Kasahara K, et al. Prostanoids and cough response to capsaicin in asthma and chronic bronchitis. Eur Respir f 1995;8:1499-505.

15 Teeter JG, Bleecker ER. Relationship between airway obstruction and respiratory symptoms in adult asthmatics. Chest 1998;113:272-7.

16 Fujimura M, Kamio Y, Hashimoto T, et al. Cough receptor sensitivity and bronchial responsiveness in patients with only chronic nonproductive cough: in view of effect of bronchodilator therapy. F Asthma 1994;31:463-72.

17 Barros MJ, Zammattio SL, Rees PJ. Effect of changes in inspiratory flow rate on cough responses to inhaled capsaicin. Clin Sci 1991;81:539-42.

18 Fujimura M, Kasahara K, Kamio Y, et al. Female gender as a determinant of cough threshold to inhaled capsaicin. Eur Respir F 1996;9:1624-6.

19 O'Connell F, Springall DR, Moradoghli-Haftvani A, et al. Abnormal intraepithelial airway nerves in persistent unexplained cough? Am f Respir Crit Care Med 1995;152:206875.

20 Stjarne P, Lundblad L, Lundberg JM, et al. Capsaicin and nicotine-sensitive afferent neurones and nasal secretion in healthy human volunteers and in patients with vasomotor rhinitis. Br f Pharmacol 1989;96:693-701.

21 Wong $\mathrm{CH}$, Morice AH. Cough threshold in patients with chronic obstructive pulmonary disease. Thorax 1999;54: $62-4$.

22 Fujimura M, Sakamoto S, Kamio Y, et al. Effect of inhaled procaterol on cough receptor sensitivity to capsaicin in patients with asthma or chronic bronchitis and in normal subjects. Thorax 1993;48:615-8.

23 Keatings VM, Barnes PJ. Granulocyte activation markers in induced sputum: comparison between chronic obstructive pulmonary disease, asthma, and normal subjects. $A m \mathcal{7}$ Respir Crit Care Med 1997;155:449-453.

24 Keatings VM, Collins PD, Scott DM, et al. Differences in interleukin-8 and tumor necrosis factor-alpha in induced sputum from patients with chronic obstructive pulmonary disease or asthma. Am 7 Respir Crit Care Med 1996;153: $530-4$.

25 Nichol G, Nix A, Barnes PJ, et al. Prostaglandin F2 alpha enhancement of capsaicin induced cough in man: modulation by beta 2 adrenergic and anticholinergic drugs. Thorax 1990; 45:694-8.

26 Nisar M, Walshaw M, Earis JE, et al. Assessment of reversibility of airway obstruction in patients with chronic obstructive airways disease. Thorax 1990;45:190-4.

27 Fujimura M, Myou S, Matsuda M, et al. Cough receptor sensitivity to capsaicin and tartaric acid in patients with Mycoplasma pneumonia. Lung 1998;176:281-8.

28 Teo WW, Chadwick IG, Kraskiewicz M, et al. Resolution of ACE inhibitor cough: changes in subjective cough and responses to inhaled capsaicin, intradermal bradykinin and substance-P. Br f Clin Pharmacol 1995;40:423-9. 